Review

\title{
From Big Data to Econophysics and Its Use to Explain Complex Phenomena
}

\author{
Paulo Ferreira ${ }^{1,2,3, * \mathbb{D}}$, Éder J.A.L. Pereira ${ }^{4,5}$ and Hernane B.B. Pereira 4,6 (D) \\ 1 VALORIZA-Research Center for Endogenous Resource Valorization, 7300-555 Portalegre, Portugal \\ 2 Department of Economic Sciences and Organizations, Instituto Politécnico de Portalegre, \\ 7300-555 Portalegre, Portugal \\ 3 Centro de Estudos e Formação Avançada em Gestão e Economia, Instituto de Investigação e Formação \\ Avançada, Universidade de Évora, Largo dos Colegiais 2, 7000 Évora, Portugal \\ 4 Programa de Modelagem Computacional, SENAI Cimatec, Av. Orlando Gomes 1845, 41 650-010 Salvador, \\ BA, Brazil; eder.johnson@ifma.edu.br (É.J.A.L.P.); hbbpereira@gmail.com (H.B.B.P.) \\ 5 Instituto Federal do Maranhão, 65075-441 São Luís-MA, Brazil \\ 6 Universidade do Estado da Bahia, 41 150-000 Salvador, BA, Brazil \\ * Correspondence: pferreira@ipportalegre.pt
}

Received: 5 June 2020; Accepted: 10 July 2020; Published: 13 July 2020

check for updates

\begin{abstract}
Big data has become a very frequent research topic, due to the increase in data availability. In this introductory paper, we make the linkage between the use of big data and Econophysics, a research field which uses a large amount of data and deals with complex systems. Different approaches such as power laws and complex networks are discussed, as possible frameworks to analyze complex phenomena that could be studied using Econophysics and resorting to big data.
\end{abstract}

Keywords: big data; complexity; networks; stock markets; power laws

\section{Introduction}

Big data has become a very popular expression in recent years, related to the advance of technology which allows, on the one hand, the recovery of a great amount of data, and on the other hand, the analysis of that data, benefiting from the increasing computational capacity of devices. Big data has been used in several research areas such as business intelligence (Chen et al. 2012; Sun et al. 2018), marketing (Verhoef et al. 2015; Wright et al. 2019), economics (Glaeser et al. 2018; Sobolevsky et al. 2017), health (Pramanik et al. 2017; Rose et al. 2019), and psychology (Matz and Netzer 2017; Adjerid and Kelley 2018), among many other areas and studies which could be mentioned.

Another area where big data is being applied is finance. In this particular case, the existence of large amounts of data allows a very broad type of analysis, from general indices to single specific assets. In particular, the use of big data allows the analysis of complex problems and has attracted the attention of physicists in recent decades. In fact, big data and complexity are intimately related to the emergence of a new research area called Econophysics.

In this paper, which is a brief introductory approach to the special issue "The Use of Big Data in Finance", we start by presenting a general view of big data and its advantages in finance (Section 2), building the bridge to Econophysics (Section 3) and some of its possible approaches, in particular, power laws and networks (Sections 4-6), and conclude the paper by including some suggestions for future research (Section 7).

\section{The Use of Big Data in Economics and Finance}

The use of big data allows the analysis of (very) large datasets, reaching conclusions for some processes which could involve complex analysis. With the growth of web access in recent decades, 
the amount of data available has increased exponentially. This large amount of available data and its use has influenced society, communication, habits, and even cultural aspects, so understanding, interpreting, and knowing how to use this amount of data has been a challenge for data scientists. In this context, big data was initially described by four different Vs: Velocity, Volume, Veracity, and Variety, as follows.

- Velocity, referring to the speed with which the data is produced, with this parameter being related to processing capacity.

- Volume, related to the amount of data to be processed.

- Veracity, referring to data feasibility.

- Variety, characterized by the heterogeneity, diversity, structures, and scales of the data.

This original V model of the big data paradigm is now added to with other data characteristics. For example, volatility, referring to the validity of the data or value referring to the potential use of the data (see, for example, Tennant et al. 2017). Other features are found in the literature, both using the initial V letter and others, like the Ps proposed by Lupton (2015), who just asks about the importance of big data in society in general and in the academic world in particular (see, for example, Kitchin and McArdle 2016 for more features). The objective of identifying big data in V was to outline the existence of different interconnected and measurable properties (Carbone et al. 2016).

The research area of finance is very sensitive to the use of this kind of approach, as there is a huge amount of data available, with some being publicly disclosed and more available in databases via subscription. Platforms such as Google, Twitter, and others give rise to the need for effective verification in terms of whether the large amount of information available on the web can help to analyze and predict financial variables (Preis et al. 2013). Verifying whether or not this large amount of information influences financial markets requires tools from complex systems (Arthur et al. 1998; Rosser 1999; Carbone et al. 2016). In this regard, the use of models, methods, and techniques available from the physics of complex systems, such as multifractal analysis, multiscalar analysis, temporal networks, or multilevel networks, have been useful in recent research and can also be useful for future research.

Another application involving big data has been developed by The Observatory of Economic Complexity (Hausmann et al. 2014), derived from the idea of the Economic Complexity Index (ECI; Hidalgo and Hausmann 2009). This index provides extensive information about more than 130 countries, making it possible to analyze the role of knowledge in the production of goods for countries' economic growth and development. Since Solow (1956), the theory of endogenous growth has contributed to the understanding of how human capital influences economic growth. However, it is also necessary to consider whether human capital is incorporated into a country's productive system by providing the production of goods with relative complexity and diversity. Thus, Hidalgo and Hausmann (2009) and Hausmann et al. (2014) created the ECI, which considers both the level of knowledge used to export goods and the diversity of production of those goods. A country has high economic complexity if the goods produced incorporate a high level of knowledge and productive diversity. One such example is Japan, which, according to ECI, had the most complex economy in the world between 2011 and 2016 due to the complexity and variety of products exported. In contrast in Botswana, which ranks 129 th according to the ECI, $52 \%$ of exports comprise only refined copper, that is, a product that requires little knowledge for manufacture.

\section{From Big Data to Econophysics}

As previously mentioned, finance is one of the areas showing increased work which could be considered as using big data, and has attracted researchers from other research fields, such as physicists, even creating multidisciplinary research fields such as econophysics.

Econophysics is a neologism used in the branch of Complex Systems from Physics seeking to make a complete survey of the statistical properties of financial markets, using the immense volume of available data and the methodologies of statistical physics (Mantegna and Stanley 1999). The term 
Econophysics was coined by Stanley et al. (1996) when they analyzed the Dow Jones Index and found that stock returns followed a power law distribution, contributing to the emergence of this new research field. Although use of the neologism is relatively recent, the approximation between physics and finance is not new, beginning probably in the 1960s, when Mandelbrot (1963), analyzing the returns of cotton prices, refutes the condition of normal asset prices (Jovanovic and Schinckus 2013, 2017). For Mirowski $(1990,1991)$, neoclassical economics had a strong influence on theoretical physics, contributing to economic theory throughout the 20th century. Mandelbrot's ideas about the non-normality of financial returns remained forgotten, until Mantegna (1991), analyzing the Italian stock market, discovered that returns were compatible with Lévy stable non-Gaussian distributions.

Since its emergence, Econophysics has made a significant contribution to several issues mainly in finance: autocorrelations, long-range dependence, and non-normal asymptotic distributions (Mantegna and Stanley 1999); assessment of financial risk and asset pricing (Bouchaud and Potters 2003); the prediction of crises and market crashes (Sornette 2017); and agent-based modeling (Farmer and Foley 2009; Lux and Marchesi 1999), systematic risk, and networks (Battiston et al. 2012a; Tabak et al. 2014; Wang et al. 2017; Wang et al. 2018).

One of the hot topics of Econophysics, where the connection to financial theory is closer, is analysis of the efficient market hypothesis (EMH). Although the EMH was only formalized by Fama (1970), this hypothesis implying that the market reflects all the available information on financial assets' prices, it was formally analyzed by Bachelier (1900) and Samuelson (1965), among others, before the definition of Econophysics. Since Fama (1970), this topic has been studied greatly in the literature (see Lee 2008; Titan 2015 for reviews). On the basis of the EMH, asset prices may be described by a random walk with this possibility being analyzed through the Hurst exponent, which is a very well-known approach in Econophysics. Methodologies like the rescaled range (R/S) analysis of Detrended Fluctuation Analysis (DFA) are widely used to make this estimation and are found in several studies, such as Costa and Vasconcelos (2003), Di Matteo et al. (2005), Wang et al. (2011a, 2011b), López and Contreras (2013), Kristoufek and Vosvrda (2013), Cao and Zhang (2015), Anagnostidis et al. (2016), Urquhart (2016), Nadarajah and Chu (2017), or Ferreira et al. (2017), among many others.

Regardless of the features identified in the previous section, it is important to understand that big data can be used for commercial and financial purposes. In different areas, firms can use their data with the objective of raising their returns (see, for example, Subrahmanyam 2019). Obviously, thanks to increased computational capacity, the financial sector can also use Econophysics models to identify, test, and evaluate models which could be used, for example, to identify patterns in financial (big) data (see, for example, Preis et al. 2010, 2012, 2013, among many others which use big data trying to anticipate possible warning signs in financial markets).

Regarded with some distrust in mainstream economics at the beginning (see, for example, Ball 2006; Schinckus 2018), this may now be changing, with some economists adopting methods originating in the field of Econophysics and increasing recognition of its wide applicability in several areas of the economy. Thus, Econophysics is slowly being assured its place. Initially, applications were restricted to financial markets and in rare cases macroeconomics. Currently, Econophysics is used in several areas of the economy, such as energy (Filip et al. 2016), regional economics (Gao and Zhou 2018), or environmental economics (Stolbova et al. 2018), among many others, demonstrating that this discipline is attaining greater importance in solving various economic problems. In complexity, an area that has gained prominence is complex networks.

\section{Power Laws in Finance}

One type of research which has gained importance in Econophysics is the investigation of power laws. While some economic models and hypotheses, such as the efficient market hypothesis of Fama (1970) and Fama (1991) and the Black and Scholes (1973) model, have assumed that returns follow a normal distribution, Econophysics has contradicted this since its emergence: if the distribution of stock returns follows a power-law distribution, this implies that large fluctuations in stock exchanges can 
occur. Accepting that financial markets are subject to wide variations can contribute to mitigation of these financial instabilities or even prevent them (Pereira et al. 2017).

The idea that stock returns follow a power-law format is recurrent in Econophysics (see, for example, Stanley et al. 1996; Lux 1996; Mantegna and Stanley 1999; or Gabaix 2009, among many others). One power-law can be defined as $y=k x^{\alpha}$, where $k$ and $\alpha$ are constants, asymptotic values of a variable $x$, like $x \rightarrow \infty$ (Newman 2005). Thus, power-laws have played an important role in economics to the extent of warranting an extensive article in the Journal of Economic Perspective (JEP), in which Gabaix (2016) demonstrates their applications in relation to finance, city size, executive salaries and macroeconomics, very different subjects.

Therefore, power laws become a stylized fact in financial time series, contributing to the interpretation of financial markets as unstable, which is noticeable during crisis episodes like the subprime one. The recognition that Econophysics approaches could be useful in the context of financial crises meant that in December 2017, the American Economic Association (AEA) hosted a conference on Econophysics attended by a group of physicists and economists with the intention of demonstrating a little more about this new research field. The positive attitude of the AEA is an important step towards achieving understanding of the two areas, economics and physics, which have always been very close. During the presentations at the AEA conference, some of the most important researchers in the new discipline were able to show some of the advances in economics and its perspectives.

\section{Complex Networks}

At the end of the 1990s, with the discovery of new network topologies such as small world (Watts and Strogatz 1998) and free of scale (Barabási and Albert 1999), the study of complex networks appeared.

The structure of a complex network is represented in the same way as a graph in a set $R$, which, in the case of networks that have no weights in their connections, is defined by $V=\left\{v_{1}, v_{2}, v_{3}, \ldots, v_{n}\right\}$ the nodes (or vertices) and $E=\left\{e_{1}, e_{2}, e_{3}, \ldots, e_{m}\right\}$, the edges or connections that link pairs of nodes. The numbers $n=|V|$ and $m=|E|$ are considered as the quantities of elements in $V$ and $E$, respectively (Newman 2018).

Complex systems, in general, involve innumerable elements organized in structures that can exist or coexist, in different scales. Most of their main characteristics emerge from interactions between their constituent parts, and cannot be predicted from an isolated understanding of each of these parts. In this context, complex networks can be located at the intersection of graph theory and statistical mechanics, involving several knowledge areas, and therefore their study can be considered as a multidisciplinary approach (Costa et al. 2007).

It can also be highlighted that complex networks have contributed to the economy by proposing new methods, techniques and properties (Schweitzer et al. 2009). In this context, one research area which benefited from these new approaches is finance, for which network theory enabled measurement of the probability of systemic risk, due to the interconnections and interdependence between the agents of a given system or market, in which the insolvency or bankruptcy of a single entity (or group of entities) can cause chain failures (Jackson 2010, 2014). In this context, Boss et al. (2004) showed that before a financial crisis, the world banks' payment systems were interconnected and had a probability distribution in the form of a power-law, meaning that a large part of the transactions involving those payment systems was concentrated in a very small number of banks, while many others traded a smaller amount.

Economists consider the importance of a payment institution according to the volume of resources it administers. However, the concept of centrality extracted from complex networks helps to classify the importance of these institutions based on how central they are in a given network (in that case, the financial system).

An important property of networks is the centrality, which quantifies the importance of the vertices (or edges) that are in a networked system. In complex networks, there is a wide variety of mathematical methods and measures of centrality of vertices that focus on different concepts and 
definitions of what it is to be central in a network. A simple measure of centrality in a network is the degree of vertex, which represents the number of edges connected to it, being considered one of the most important network metrics (Newman 2018).

\section{Dynamics in Complex Networks}

Considering the concept previously described, Battiston et al. (2012b, 2016) propose that instead of considering financial institutions "too big to fail" in terms of default risk, they can be considered "too central to fail", i.e., monitoring the centrality of a financial institution rather than its size. This may better explain how a crisis can spread in a banking system, as negative shocks to central financial institutions can cause a system-wide contagion effect. When it is discovered that there are too many central markets to break, this implies that some relevant financial markets, such as those of the European Union or the United States, have a high centrality and any disturbance in them can affect, practically, the entire network which is connected to them (Pereira et al. 2019).

In fact, one of the most interesting and relevant issues in networks is related to their dynamics, found in several complex systems, and not only in finance, with dynamic issues like congestion, cascading failures, spreading, and synchronization often being identified (Motter et al. 2006; Lorenz et al. 2009; Elliott et al. 2014). These concepts are intimately related to the diffusion of information and networks' capacity to pass problems from vital nodes to the other network members (Jalili and Perc 2017). Related to the connectivity of the networks, these dynamics could imply a greater or lesser possibility of contagion (Gai and Kapadia 2010), which is often described in the literature.

Complex networks have influenced analysis in finance, as in, for example Haldane and May (2011), who analyzed the banking system as an ecological network susceptible to financial risks due to its topology. Diebold and Yilmaz (2014), using complex networks, demonstrate that during the period preceding the 2008 crisis, markets were more connected and more subject to instability. Highlighted among studies relating complex networks and the contagion effect are Gai and Kapadia (2010), Glasserman and Young (2015), or Acemoglu et al. (2015), who analyze the risk of financial networks and propose that financial contagion shows a form of transition phase, and to a certain extent, strong interconnections serve as a shock propagation mechanism, leading to the fragility of a given network. It is crucial to analyze the changing relevance of the nodes, according to Bartesaghi et al. (2020), which in the context of crises and their potential financial implications, could also be an interesting issue for analysis using big data.

\section{Conclusions}

Big data and complexity go hand in hand and Econophysics is a way to use this kind of data, with the particularity of being used mainly in finance. The availability of large datasets, jointly with increased computational processing, made big data and finance very attractive research areas in general, of particular interest in the analysis of crisis events.

Since the global financial crisis, governments around the world have been acting to improve financial stability and reduce the risks of a highly interconnected financial system, using complexity to do so (Yellen 2013). That said, complexity has been providing methods and models that try to explain the instabilities occurring in different markets, leaving five important lessons for financial markets:

1. Extreme events can occur in stock markets.

2. The financial markets are interconnected.

3. Some sectors or companies are too central to fail.

4. Different systems, for example, public health, transport, industry, and finance, are interrelated, increasing the global risk.

5. Financial crises can be complex phenomena, when markets are in a transition phase, when any "shock" can cause a crisis and the consequent contagion effect. 
In the current context, where we are facing the Covid-19 crisis, which could be considered as a complex phenomenon (Wagner 2020), risk analysis is raised to another level, requiring the monitoring of several issues lying beyond economic or financial topics, and that risk analysis must incorporate issues related to the environment (for example, increased deforestation in the Amazon or global climate change), public health (spread of this or other epidemics), politics (corruption), credit (more than the usual default analysis, for example, the high university student debt in the USA), and energy (the dependence on oil from regions in geopolitical conflicts), among others. Therefore, there is a need for complexity to understand instability, in particular, high risks due to a globalized, interconnected world with a large volume of information. For all of these kinds of complex problems, the use of big data could be the solution to help authorities prepare for possible future challenges.

Considering the potential of studying the effects of the current crisis, future research could focus, for example, on the linkage between Google trends and this particular disease. It has already attracted the attention of some authors, for example, Effenberger et al. (2020), who relate the public interest of the disease with the number of new reported cases. In fact, the use of Google trends opens a wide set of possibilities for academic literature in general and for the study of economics and finance in particular. Recent studies such as Salisu et al. (2020) or Simionescu et al. (2020) show the possibilities of using this measure. Certainly, it could also be used in other contexts, such as the relationship between Google trends and investor sentiment. This linkage already exists (see, for example, Bank et al. 2011; Kim et al. 2019; or El Alaoui et al. 2020, among many others) and could be used in the future to relate investor sentiment and financial markets during the COVID crisis but after, in recovery from the pandemic.

Recently, many studies have used high-frequency data in the analysis of financial markets, which could also be explored to analyze the effects of Covid (Corbet et al. 2020). Despite the interest of using high-frequency data, even in the context of Econophysics methods to study financial markets' multiscale and multifractality behaviors, it is also important to take into account the quality of big data, in particular, that of high frequency data. However, it is clear that the use of big data could have a direct impact on management practices, as it fosters the development of organizations' knowledge (Choi et al. 2017; Dugast and Foucault 2018), including financial firms' risk management (Campbell-Verduyn et al. 2017; Fang and Zhang 2016). Moreover, the use of big data could have an impact on reducing costs for firms and also for analysts, making activities more efficient in this domain (Fanning and Grant 2013; Li et al. 2015; Lee 2017).

Author Contributions: Conceptualization, P.F., É.J.A.L.P., and H.B.B.P.; formal analysis, P.F., É.J.A.L.P., and H.B.B.P.; writing—original draft preparation, P.F., É.J.A.L.P., and H.B.B.P.; writing—review and editing, P.F., É.J.A.L.P., and H.B.B.P. All authors have read and agreed to the published version of the manuscript.

Funding: Paulo Ferreira acknowledges the financial support of Fundação para a Ciência e a Tecnologia (grants UIDB/05064/2020 and UIDB/04007/2020). Éder Pereira is pleased to acknowledge financial support from Fundação de Amparo e Pesquisa do Estado da Bahia_FAPESB (grant number BOL 0261/2017).

Conflicts of Interest: The authors declare no conflict of interest.

\section{References}

Acemoglu, Daron, Asuman Ozdaglar, and Alireza Tahbaz-Salehi. 2015. Systemic risk and stability in financial networks. American Economic Review 105: 564-608. [CrossRef]

Adjerid, Idris, and Ken Kelley. 2018. Big data in psychology: A framework for research advancement. American Psychologist 73: 899-917. [CrossRef] [PubMed]

Anagnostidis, Panagiotis, Christos Varsakelis, and Christos Emmanouilides. 2016. Has the 2008 financial crisis affected stock market efficiency? The case of Eurozone. Physica A 447: 116-28. [CrossRef]

Arthur, William, Steven Durlauf, and David Lane. 1998. Introduction to the Economy as an Evolving Complex System II. Madison: University of Wisconsin-Madison.

Bachelier, Louis. 1900. Théorie de la speculation. Annales Scientifiques de l'École Normale Supérieure 17: 21-86. [CrossRef]

Ball, Philip. 2006. Culture crash. Nature 441: 686-88. [CrossRef] [PubMed] 
Bank, Martin, Martin Larch, and Georg Peter. 2011. Google search volume and its influence on liquidity and returns of German stocks. Financial Markets and Portfolio Management 25: 239-64. [CrossRef]

Barabási, Albert-László, and Réka Albert. 1999. Emergence of scaling in random networks. Science 286: 509-12. [CrossRef]

Bartesaghi, Paolo, Michele Benzi, Gian Paolo Clemente, Rosanna Grassi, and Ernesto Estrada. 2020. Risk-Dependent Centrality in Economic and Financial Networks. SIAM Journal on Financial Mathematics 11: 526-65. [CrossRef]

Battiston, Stefano, Domenico Gatti, Mauro Gallegati, Bruce Greenwald, and Joseph Stiglitz. 2012a. Liaisons dangereuses: Increasing connectivity, risk sharing, and systemic risk. Journal of Economic Dynamics and Control 36: 1121-41. [CrossRef]

Battiston, Stefano, J. Doyne Farmer, Andreas Flache, Diego Garlaschelli, Hans Heesterbeek, Andrew Haldane, Cars Hommes, Carlo Jaeger, Robert May, and Marten Scheffer. 2016. Complexity theory and financial regulation. Science 351: 818-19. [CrossRef]

Battiston, Stefano, Michelangelo Puliga, Rahul Kaushik, Paolo Tasca, and Guido Caldarelli. 2012b. Debtrank: Too central to fail? financial networks, the fed and systemic risk. Scientific Reports 2: 541. [CrossRef] [PubMed]

Black, Fischer, and Myron Scholes. 1973. The pricing of options and corporate liabilities. Journal of Political Economy 81: 637-54. [CrossRef]

Boss, Michael, Helmut Elsinger, Martin Summer, and Stefan Thurner. 2004. Network topology of the interbank market. Quantitative Finance 4: 677-84. [CrossRef]

Bouchaud, Jean-Phillipe, and Marc Potters. 2003. Theory of Financial Risk and Derivative Pricing: From Statistical Physics to Risk Management. Cambridge: Cambridge University Press.

Campbell-Verduyn, Malcolm, Marcel Goguen, and Tony Porter. 2017. Big Data and algorithmic governance: The case of financial practices. New Political Economy 22: 219-36. [CrossRef]

Cao, Guangxi, and Minjia Zhang. 2015. Extreme values in the Chinese and American stock markets based on detrended fluctuation analysis. Physica A 436: 25-35. [CrossRef]

Carbone, Anna, Meiko Jensen, and Aki-Hiro Sato. 2016. Challenges in data science: A complex systems perspective. Chaos, Solitons \& Fractals 90: 1-7.

Chen, Hsinchun, Roger Chiang, and Veda Storey. 2012. Business Intelligence and Analytics: From Big Data to Big Impact. MIS Quarterly 36: 1165-88. [CrossRef]

Choi, Tsan-Ming, Hing Chan, and Xiaohang Yue. 2017. Recent Development in Big Data Analytics for Business Operations and Risk Management. IEEE Transactions on Cybernetics 47: 81-92. [CrossRef]

Corbet, Shaen, Charles Larkin, and Brian Lucey. 2020. The contagion effects of the COVID-19 pandemic: Evidence from gold and cryptocurrencies. Finance Research Letters 35: 101554. [CrossRef]

Costa, Luciano, Francisco Rodrigues, Gonzalo Travieso, and Paulino Villas Boas. 2007. Characterization of complex networks: A survey of measurements. Advances in Physics 56: 167-242. [CrossRef]

Costa, Rogério, and Giovani Vasconcelos. 2003. Long-range correlations and nonstationarity in the Brazilian stock market. Physica A 329: 231-48. [CrossRef]

Di Matteo, Tiziana, Tomaso Aste, and Michel Dacorogna. 2005. Long-term memories of developed and emerging markets: Using the scaling analysis to characterize their stage of development. Journal of Banking \& Finance 29: 827-51.

Diebold, Francis, and Kamil Yilmaz. 2014. On the network topology of variance decompositions: Measuring the connectedness of financial firms. Journal of Econometrics 182: 119-34. [CrossRef]

Dugast, Jérôme, and Thierry Foucault. 2018. Data abundance and asset price informativeness. Journal of Financial Economics 130: 367-91. [CrossRef]

Effenberger, Maria, Andreas Kronbichler, Jae Shin, Gert Mayer, Herbert Tilg, and Paul Perco. 2020. Association of the COVID-19 pandemic with Internet Search Volumes: A Google Trends Analysis. International Journal of Infectious Diseases 95: 192-97. [CrossRef] [PubMed]

El Alaoui, Marwane, Elie Bouri, and Nehme Azoury. 2020. The determinants of the US consumer sentiment: 3 Linear and nonlinear models. International Journal of Financial Studies 8: 38. [CrossRef]

Elliott, Matthew, Benjamin Golub, and Matthew Jackson. 2014. Financial Networks and Contagion. American Economic Review 104: 3115-53. [CrossRef]

Fama, Eugene. 1970. Efficient capital markets: A review of theory and empirical work. The Journal of Finance 25: 383-417. [CrossRef] 
Fama, Eugene. 1991. Efficient capital markets: II. The Journal of Finance 46: 1575-617. [CrossRef]

Fang, Bin, and Peng Zhang. 2016. Big Data in Finance. In Big Data Concepts, Theories, and Applications. Edited by Shui Yu and Song Guo. Cham: Springer, pp. 391-412.

Fanning, Kurt, and Rita Grant. 2013. Big Data: Implications for Financial Managers. The Journal of Corporate Accounting and Finance 24: 23-30. [CrossRef]

Farmer, J. Doyne, and Duncan Foley. 2009. The economy needs agent-based modelling. Nature 460: 685. [CrossRef] [PubMed]

Ferreira, Paulo, Luís Loures, José Nunes, and Andreia Dionísio. 2017. The behaviour of share returns of football clubs: An econophysics approach. Physica A 472: 136-44. [CrossRef]

Filip, Ondrej, Karel Janda, Ladislav Kristoufek, and David Zilberman. 2016. Dynamics and evolution of the role of biofuels in global commodity and financial markets. Nature Energy 1: 16169. [CrossRef]

Gabaix, Xavier. 2009. Power laws in economics and finance. The Annual Review of Economics 1: 255-94. [CrossRef]

Gabaix, Xavier. 2016. Power laws in economics: An introduction. Journal of Economic Perspectives 30: 185-206. [CrossRef]

Gai, Prasanna, and Sujit Kapadia. 2010. Contagion in financial networks. Proceedings of the Royal Society A: Mathematical, Physical and Engineering Sciences 466: 2401-23. [CrossRef]

Gao, Jian, and Tao Zhou. 2018. Quantifying China's regional economic complexity. Physica A 492: 1591-603. [CrossRef]

Glaeser, Edward, Scott Kominers, Michael Luca, and Nikhil Naik. 2018. Big data and big cities: The promises and limitations of improved measures of urban life. Economic Inquiry 56: 114-37. [CrossRef]

Glasserman, Paul, and Hobart Young. 2015. How likely is contagion in financial networks? Journal of Banking $\mathcal{E}$ Finance 50: 383-99.

Haldane, Andrew, and Robert May. 2011. Systemic risk in banking ecosystems. Nature 469: 351-55. [CrossRef]

Hausmann, Ricardo, César Hidalgo, Sebastián Bustos, Michele Coscia, Alexander Simoes, and Muhmmad Yildirim. 2014. The Atlas of Economic Complexity: Mapping Paths to Prosperity. Cambridge: MIT Press.

Hidalgo, César, and Ricardo Hausmann. 2009. The building blocks of economic complexity. Proceedings of the National Academy of Sciences 106: 10570-75. [CrossRef] [PubMed]

Jackson, Matthew. 2010. Social and economic networks. Princeton: Princeton University Press.

Jackson, Matthew. 2014. Networks in the understanding of economic behaviors. Journal of Economic Perspectives 28: 3-22. [CrossRef]

Jalili, Mahdi, and Matjaz Perc. 2017. Information cascades in complex networks. Journal of Complex Networks 5: 665-93. [CrossRef]

Jovanovic, Franck, and Christophe Schinckus. 2013. Econophysics: A new challenge for financial economics? Journal of the History of Economic Thought 35: 319-52. [CrossRef]

Jovanovic, Franck, and Christophe Schinckus. 2017. Econophysics and Financial Economics: An Emerging Dialogue. Oxford: Oxford University Press.

Kim, Neri, Katarína Lučivjanská, Peter Molnár, and Roviel Villa. 2019. Google searches and stock market activity: Evidence from Norway. Finance Research Letters 28: 208-20. [CrossRef]

Kitchin, Rob, and Gavin McArdle. 2016. What makes Big Data, Big Data? Exploring the ontological characteristics of 26 datasets. Big Data $\mathcal{E}$ Society 3: 1-10.

Kristoufek, Ladislav, and Miloslav Vosvrda. 2013. Measuring capital market efficiency: Global and local correlations structure. Physica A 392: 184-93. [CrossRef]

Lee, Cheng-Few. 2008. Efficient market hypothesis (EMH): Past, present and future. Review of Pacific Basin Financial Markets and Policies 11: 305-29.

Lee, In. 2017. Big data: Dimensions, evolution, impacts, and challenges. Business Horizons 60: 293-303. [CrossRef]

Li, Jingran, Fei Tao, Ying Cheng, and Liangjin Zhao. 2015. Big Data in product lifecycle management. The International Journal of Advanced Manufacturing Technology 81: 667-84.

López, Juan, and Jesús Contreras. 2013. Performance of multifractal detrended fluctuation analysis on short time series. Physical Review E 87: 022918. [CrossRef] [PubMed]

Lorenz, Jan, Stefano Battiston, and Franck Schweitzer. 2009. Systemic risk in a unifying framework for cascading processeson networks. The European Physical Journal B 71: 441-60. [CrossRef]

Lupton, Debora. 2015. The Thirteen Ps of Big Data [Blog Post]. Available online: https://simplysociology. wordpress.com/2015/05/11/the-thirteen-ps-of-big-data/ (accessed on 1 July 2020). 
Lux, Thomas, and Michele Marchesi. 1999. Scaling and criticality in a stochastic multi-agent model of a financial market. Nature 97: 498-500. [CrossRef]

Lux, Thomas. 1996. The stable paretian hypothesis and the frequency of large returns: An examination of major German stocks. Applied Financial Economics 6: 463-75. [CrossRef]

Mandelbrot, Benoit. 1963. New methods in statistical economics. Journal of Political Economy 71: 421-40. [CrossRef]

Mantegna, Rosario, and Harry Stanley. 1999. Introduction to Econophysics: Correlations and Complexity in Finance. Cambridge: Cambridge University Press.

Mantegna, Rosario. 1991. Lévy walks and enhanced diffusion in Milan stock exchange. Physica A 179: $232-42$. [CrossRef]

Matz, Sandra, and Odez Netzer. 2017. Using Big Data as a window into consumers' psychology. Current Opinion in Behavioral Sciences 18: 7-12. [CrossRef]

Mirowski, Philip. 1990. From Mandelbrot to chaos in economic theory. Southern Economic Journal 57: $289-307$. [CrossRef]

Mirowski, Philip. 1991. More Heat than Light: Economics as Social Physics, Physics as Nature's Economics. Cambridge: Cambridge University Press.

Motter, Adilson, Manuel Matías, Jürgen Kurths, and Edward Ott. 2006. Dynamics on Complex Networks and Applications. Physica D: Nonlinear Phenomena 224: vii-viii. [CrossRef]

Nadarajah, Saralees, and Jeffrey Chu. 2017. On the inefficiency of Bitcoin. Economics Letters 150: 6-9. [CrossRef]

Newman, Mark. 2005. Power, laws, pareto distributions and zipf's law. Contemporary Physics 46: $323-51$. [CrossRef]

Newman, Mark. 2018. Networks. Oxford: Oxford University Press.

Pereira, Éder, Marcus Silva, and Hernane Pereira. 2017. Econophysics: Past and present. Physica A 473: 251-61. [CrossRef]

Pereira, Éder, Paulo Ferreira, Marcus Silva, José Miranda, and Hernane Pereira. 2019. Multiscale network for 20 stock markets using DCCA. Physica A 529: 121542. [CrossRef]

Pramanik, Ileas, Raymond Lau, Haluk Demirkan, and Abul Azad. 2017. Smart health: Big data enabled health paradigm within smart cities. Expert Systems with Applications 87: 370-83. [CrossRef]

Preis, Tobias, Daniel Reith, and Harry Stanley. 2010. Complex Dynamics of Our Economic Life on Different Scales: Insights from Search Engine Query Data. Philosophical Transactions of the Royal Society A: Mathematical, Physical and Engineering Sciences 368: 5707-19. [CrossRef]

Preis, Tobias, Dror Kennett, Harry Stanley, Dirk Helbing, and Eshel Ben-Jacob. 2012. Quantifying the Behavior of Stock Correlations under Market Stress. Scientific Reports 2: 752. [CrossRef]

Preis, Tobias, Helen Moat, and Harry Stanley. 2013. Quantifying trading behavior in financial markets using Google Trends. Scientific Reports 3: 1684. [CrossRef]

Rose, Sophia, Kévin Contrepois, Kegan Moneghetti, Wenyu Zhou, Tejaswini Mishra, Samson Mataraso, Orit Dagan-Rosenfeld, Ariel Ganz, Jessilyn Dunn, Daniel Hornburg, and et al. 2019. A longitudinal big data approach for precision health. Nature Medicine 25: 792-804.

Rosser, John. 1999. On the complexities of complex economic dynamics. Journal of Economic Perspectives 13: 169-92. [CrossRef]

Salisu, Afees, Ahamuefula Ogbonna, and Adelou Adewuyi. 2020. Google trends and the predictability of precious metals. Resources Policy 65: 101542. [CrossRef]

Samuelson, Paul. 1965. Proof that properly anticipated prices fluctuate randomly. Industrial Management Review 6: 41-49.

Schinckus, Christophe. 2018. When Physics Became Undisciplined: An Essay on Econophysics. Doctoral dissertation, University of Cambridge. Available online: https://www.repository.cam.ac.uk/bitstream/handle/ 1810/279683/Chris_Thesis_FINAL.pdf?sequence=5\&isAllowed=y (accessed on 4 June 2020).

Schweitzer, Frank, Giorgio Fagiolo, Didier Sornette, Fernando Vega-Redondo, Alessando Vespignani, and Douglas White. 2009. Economic networks: The new challenges. Science 325: 422-25. [CrossRef] [PubMed]

Simionescu, Mihaela, Dalia Streimikiene, and Wadim Strielkowski. 2020. What Does Google Trends Tell Us about the Impact of Brexit on the Unemployment Rate in the UK? Sustainability 12: 1011. [CrossRef] 
Sobolevsky, Stanislav, Emanuele Massaro, Iva Bojic, Juan Arias, and Carlo Ratti. 2017. Predicting regional economic indices using big data of individual bank card transactions. Paper presented at IEEE International Conference on Big Data (Big Data), Boston, MA, USA, September 18-20; pp. 1313-18.

Solow, Robert. 1956. A Contribution to the Theory of Economic Growth. The Quarterly Journal of Economics 70 : 65-94. [CrossRef]

Sornette, Didier. 2017. Why Stock Markets Crash: Critical Events in Complex Financial Systems. Princeton: Princeton University Press.

Stanley, Harry, Vsevolo Afanasyev, Luís Amaral, Sergey Buldyrev, Ary Goldberger, Shlomo Havlin, Heiko Leschorn, Philipp Maass, Rosario Mantegna, Chung-Kang Peng, and et al. 1996. Anomalous fluctuations in the dynamics of complex systems: From DNA and physiology to econophysics. Physica A 224: 302-21. [CrossRef]

Stolbova, Veronika, Irene Monasterolo, and Stefano Battiston. 2018. A financial macro-network approach to climate policy evaluation. Ecological Economics 149: 239-53. [CrossRef]

Subrahmanyam, Avanidhar. 2019. Big data in finance: Evidence and challenges. Borsa Istanbul Review 19: $283-87$. [CrossRef]

Sun, Zhaohao, Lizhe Sun, and Kenneth Strang. 2018. Big Data Analytics Services for Enhancing Business Intelligence. Journal of Computer Information Systems 58: 162-69. [CrossRef]

Tabak, Benjamin, Marcelo Takami, Jadson Rocha, Daniel Cajueiro, and Sergio Souza. 2014. Directed clustering coefficient as a measure of systemic risk in complex banking networks. Physica A 394: 211-16. [CrossRef]

Tennant, Mark, Frederic Stahl, Omer Rana, and João Gomes. 2017. Scalable real-time classification of data streams with concept drift. Future Generation Computer Systems 75: 187-99. [CrossRef]

Titan, Alexandra. 2015. The Efficient Market Hypothesis: Review of Specialized Literature and Empirical Research. Procedia Economics and Finance 32: 442-49. [CrossRef]

Urquhart, Andrew. 2016. The inefficiency of Bitcoin. Economics Letters 148: 80-82. [CrossRef]

Verhoef, Peter, Edwin Kooge, and Natasha Walk. 2015. Creating Value with Big Data Analytics. London: Routledge.

Wagner, Alexanfer. 2020. What the stock market tells us about the post-COVID-19 world. Nature Human Behaviour 4: 440. [CrossRef] [PubMed]

Wang, Gang-Jin, Chi Xie, Kaijian He, and Harry Stanley. 2017. Extreme risk spillover network: Application to financial institutions. Quantitative Finance 17: 1417-33. [CrossRef]

Wang, Gang-Jin, Zhi-Qiang Jiang, Min Lin, Chi Xie, and Harry Stanley. 2018. Interconnectedness and systemic risk of China's financial institutions. Emerging Markets Review 35: 1-18. [CrossRef]

Wang, Yudong, Yu Wei, and Chongfeng Wu. 2011a. Analysis of the efficiency and multifractality of gold markets based on multifractal detrended fluctuation analysis. Physica A 390: 817-27. [CrossRef]

Wang, Yudong, Yu Wei, and Chongfeng Wu. 2011b. Detrended fluctuation analysis on spot and futures markets of West Texas Intermediate crude oil. Physica A 390: 864-75. [CrossRef]

Watts, Duncan, and Steven Strogatz. 1998. Collective dynamics of 'small-world' networks. Nature 393: 440. [CrossRef]

Wright, Len, Robin Robin, Merlin Stone, and Eleni Aravopoulou. 2019. Adoption of Big Data Technology for Innovation in B2B Marketing. Journal of Business-to-Business Marketing 26: 281-93. [CrossRef]

Yellen, Janet. 2013. Interconnectedness and Systemic Risk: Lessons from the Financial Crisis and Policy Implications: A Speech at the American Economic Association/American Finance Association Joint Luncheon, San Diego, California, January 4, 2013 (No. 631). Washington, DC: Board of Governors of the Federal Reserve System (US).

(C) 2020 by the authors. Licensee MDPI, Basel, Switzerland. This article is an open access article distributed under the terms and conditions of the Creative Commons Attribution (CC BY) license (http://creativecommons.org/licenses/by/4.0/). 